\title{
Evaluation of Patchouli (Pogostemon cablin Benth.) cultivars for growth, yield and quality parameters
}

\begin{abstract}
The present study was conducted to evaluate six different Patchouli cultivars for growth, yield and quality parameters with respect to patchouli alcohol. During the plant growth, significant differences were observed in plant height with respect to cultivars. Among all the cultivars, KSM 4 was found to be superior with maximum plant height $(95.7 \mathrm{~cm})$, more number of branches per plant (37.3), more number of leaves per plant (689) and broader leaf area $(6509 \mathrm{~cm} 2)$. The average fresh herbage yield (686 g/plant), oil content $(2.8 \%)$, oil yield $(19.3 \mathrm{~g})$ and patchouli alcohol content $(34.09 \%)$ of KSM 4 were also found to be remarkable when compared to other cultivars. The next best cultivar was found to be KSM 5 in terms of growth and yield parameters. From the present study, it is apparent that a significant chemical variation of essential oil existed among the Patchouli cultivars. This clearly indicates that the oil quantity and quality is not only influenced by environmental factors such as, soil, climate and distillation practices, but also depends on genotype of cultivar. Hence, we can recommend KSM 4 as the best cultivar for commercial cultivation under south Indian climatic condition.
\end{abstract}

Keyword: Pogostemon cablin; Cultivar; Yield; Essential oil; Cultivation evaluation 